\title{
Merlin/ERM proteins establish cortical asymmetry and centrosome position
}

\author{
Alan M. Hebert, ${ }^{1,2}$ Brian DuBoff,, ${ }^{1,2}$ Jessica B. Casaletto, ${ }^{1,2}$ Andrew B. Gladden,, \\ and Andrea I. McClatchey ${ }^{1,2,3}$ \\ ${ }^{1}$ Massachusetts General Hospital Center for Cancer Research, Charlestown, Massachusetts 02129, USA; ${ }^{2}$ Department \\ of Pathology, Harvard Medical School, Charlestown, Massachusetts 02129, USA
}

\begin{abstract}
The ability to generate asymmetry at the cell cortex underlies cell polarization and asymmetric cell division. Here we demonstrate a novel role for the tumor suppressor Merlin and closely related ERM proteins (Ezrin, Radixin, and Moesin) in generating cortical asymmetry in the absence of external cues. Our data reveal that Merlin functions to restrict the cortical distribution of the actin regulator Ezrin, which in turn positions the interphase centrosome in single epithelial cells and three-dimensional organotypic cultures. In the absence of Merlin, ectopic cortical Ezrin yields mispositioned centrosomes, misoriented spindles, and aberrant epithelial architecture. Furthermore, in tumor cells with centrosome amplification, the failure to restrict cortical Ezrin abolishes centrosome clustering, yielding multipolar mitoses. These data uncover fundamental roles for Merlin/ERM proteins in spatiotemporally organizing the cell cortex and suggest that Merlin's role in restricting cortical Ezrin may contribute to tumorigenesis by disrupting cell polarity, spindle orientation, and, potentially, genome stability.
\end{abstract}

[Keywords: Merlin/ERMs; $\alpha$-catenin; polarity; centrosome; spindle orientation; cortical cytoskeleton]

Supplemental material is available for this article.

Received April 13, 2012; revised version accepted October 25, 2012.

The ability to spatially restrict specific activities across the cell cortex functionally defines individual cell types and tissues. Cortical asymmetry is achieved via the polarized distribution of membrane protein complexes and mechanical properties across the cortex. In single cells and single-celled organisms, cortical asymmetry can be triggered by external cues such as sperm entry or by the cortical scar that marks the site of an earlier division (Macara and Mili 2008; St Johnston and Ahringer 2010). In multicellular tissues, cortical asymmetry can be guided by cell-cell and/or cell-extracellular matrix (ECM) interaction (St Johnston and Ahringer 2010). Much less is known about how or even whether cells can intrinsically establish cortical asymmetry in the absence of external cues.

A central consequence of cortical asymmetry in singleand multicellular organisms is the orientation and morphology of the mitotic spindle, which dictates whether divisions will be symmetric or asymmetric and yield faithful chromosome segregation (Siller and Doe 2009; Pereira and Yamashita 2011). In multicellular organisms, aberrant spindle orientation can cause defective tissue architecture and stem cell gain/loss, while aberrant spindle morphology can yield chromosome missegrega-

${ }^{3}$ Corresponding author

E-mail mcclatch@helix.mgh.harvard.edu

Article is online at http://www.genesdev.org/cgi/doi/10.1101/gad.194027.112. tion and aneuploidy—phenotypes that are all known to contribute to tumorigenesis (Bettencourt-Dias et al. 2011; Morin and Bellaiche 2011). Both the physical properties of the cell cortex and communication between the cortex and centrosomes at the spindle poles are known to be critical for spindle orientation and function (Sandquist et al. 2011). The molecular mechanisms by which cortical cues direct spindle orientation and function must involve the dynamic spatiotemporal organization of the cell cortex.

The cell cortex is defined by dynamic interactions between plasma membrane proteins and/or lipids and the underlying cortical cytoskeleton (Fehon et al. 2010; Rauzi and Lenne 2011). The ERM proteins (Ezrin, Radixin, and Moesin) and closely related neurofibromatosis type 2 (NF2) tumor suppressor Merlin are scaffolds that can assemble protein complexes at the membrane:cytoskeleton interface and may play important roles in cortical organization (McClatchey and Fehon 2009). For example, by linking plasma membrane proteins and/or lipids directly to cortical actin, activated ERM proteins can physically stabilize the cell cortex during mitotic rounding, membrane bleb retraction, and the establishment of the apical and apical junctional region of epithelial cells (Gobel et al. 2004; Saotome et al. 2004; Van Furden et al. 2004; Charras et al. 2006; Pilot et al. 2006; Kunda et al. 2008; Luxenburg et al. 2011). ERM proteins can also control the distribution and activity of the numerous membrane receptors 
with which they interact (McClatchey and Fehon 2009). Similarly, functional studies indicate that cortical Merlin can both control the distribution of certain membrane receptors and regulate cortical features such as cell junctions, apical integrity, and spindle orientation cues (Lallemand et al. 2003, 2009; Maitra et al. 2006; Curto et al. 2007; Cole et al. 2008; Gladden et al. 2010; Yi et al. 2011). Merlin and the ERM proteins share strong evolutionary conservation and are thought to be derived from a common ancestor. They are coexpressed in most cell types, share binding partners, hetero-oligomerize, and display coordinated regulation yet often exhibit distinct cortical localizations (McClatchey and Fehon 2009). Moreover, in contrast to the ERM proteins, Merlin is an established tumor suppressor in flies, mice, and humans (Rouleau et al. 1993; Trofatter et al. 1993; LaJeunesse et al. 1998; McClatchey et al. 1998). Indeed, the nature of the functional relationship between Merlin and the ERM proteins is not clear, and we lack a fundamental understanding of how Merlin/ERM proteins organize the cell cortex.

Here we show that cortical Ezrin undergoes a progressive cell cycle-correlated redistribution and concentration in single colonic epithelial cells in the absence of external cues. The restricted distribution of Ezrin, in turn, intrinsically and actively positions the interphase centrosome and ensuing mitotic spindle. Importantly, Merlin functions to restrict the cortical distribution of Ezrin in single cells, in derivative three-dimensional (3D) organotypic cultures, and in vivo. Merlin-mediated restriction of Ezrin is dependent on the Merlin-interacting protein $\alpha$-catenin even in single cells, revealing a novel junction-independent function for $\alpha$-catenin in establishing cortical asymmetry. In the absence of Merlin, ectopic Ezrin yields mispositioned centrosomes, aberrant mitotic spindle orientation, and defective epithelial architecture. The importance of Merlin-mediated restriction of cortical Ezrin is exemplified by the fact that in tumor cells containing supernumerary centrosomes, loss of Merlin yields centrosome unclustering and multipolar spindles, suggesting that Ezrin is a key component of the poorly understood phenomenon of centrosome clustering. In fact, centrosome unclustering is a feature of NF2-deficient human mesothelioma cells that is reverted by reintroduction of NF2 expression. Thus, Ezrin and Merlin are central components of a program whereby the intrinsic spatiotemporal organization of the cell cortex governs polarity, centrosome position, and mitotic spindle orientation and function.

\section{Results}

\section{Cell cycle-dependent distribution of cortical Ezrin} in single cells

To follow the localization of Ezrin and Merlin as individual cells establish apical-basal polarity during epithelial morphogenesis, we used the well-established model of Caco2 intestinal epithelial cyst formation in Matrigel (Jaffe et al. 2008). Consistent with previous reports, we found that Ezrin concentrated at the cleavage furrow and nascent apical lumen at the two-cell stage and remained apically concentrated as the two-cell structures developed into fully polarized cysts with a single central lumen (Fig. 1A; Jaffe et al. 2008). Surprisingly, however, we found that Ezrin also concentrated into a distinct caplike structure at the membrane of single spherical cells prior to the first cell division (Fig. 1B). At early times after plating, Ezrin localized uniformly around the cortex of single cells, indicating that the Ezrin "cap" is not a remnant of the apical surface established in two-dimensional (2D) cultures and instead forms de novo via the progressive restriction of Ezrin into a small cortical domain (Fig. 1B; Supplemental Fig. S1A). Single Caco2 cells are uniformly surrounded by Matrigel prior to Ezrin cap formation; thus, cell-ECM attachment does not initiate cortical asymmetry in this system. The formation of an Ezrin cap therefore reflects the intrinsic establishment of cortical asymmetry in the absence of external cues.

Ezrin can directly interact with and stabilize cortical actin filaments (Algrain et al. 1993; Turunen et al. 1994). Consistent with this, we found that cortical actin is markedly concentrated directly beneath the mature Ezrin cap (Fig. 1B). Importantly, apical/apical junctional markers such as aPKC, Par3, and ZO-1 were not concentrated at the Ezrin cap, and the cap was devoid of microvilli (Fig. 1C; Supplemental Fig. S1B,C), indicating that it does not yet represent a bona fide apical surface. Furthermore, E-cadherin was uniformly localized around the cortex in capping cells in the absence of adherens junctions (AJs) (Supplemental Fig. S1D). Thus, Ezrin forms a distinct cortical domain in single epithelial cells prior to the establishment of apico-basal polarity and in the absence of external cues.

To determine whether the dynamic restriction of Ezrin into a cap is linked to the cell cycle, we labeled single Caco 2 cells with EdU and stained for phospho-histone $\mathrm{H} 3$ (pHH3) to mark cells that have entered S phase or mitosis, respectively. At a time when about half $(\sim 53 \%)$ of the cells have a mature cap, the majority $(85.1 \%)$ of those cells were EdU- or EdU/pHH3-positive, and a small percentage $(14.9 \%)$ were EdU/pHH3-negative; in contrast, nearly all cells that exhibited a partial restriction of cortical Ezrin were EdU/pHH3-negative (Fig. 1D; Supplemental Fig. S1E). These data indicate that the restriction of cortical Ezrin occurs during G1 and is largely completed by $\mathrm{S}$ phase. Thus, the formation of a cortical Ezrin cap is a very early indication of a cell's pending entry into $S$ phase.

\section{Requirements for Ezrin cap formation}

The relationship between Ezrin and cortical actin seems to be reciprocal. For example, during mitotic cell rounding, cortical actin is necessary for the activation and localization of ERM proteins, which in turn organize cortical actin filaments and stiffen the cortex (Thery et al. 2005; Carreno et al. 2008; Kunda et al. 2008; Luxenburg et al. 2011). Indeed, while actin is markedly concentrated beneath the Ezrin cap, we also found that Ezrin cap 
A

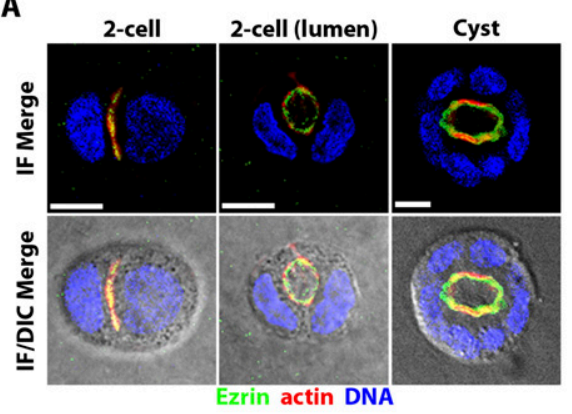

B

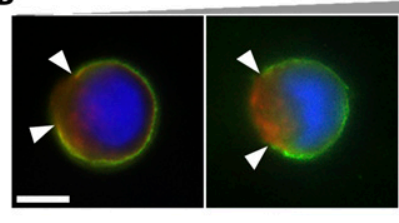

$\Delta$ time after plating

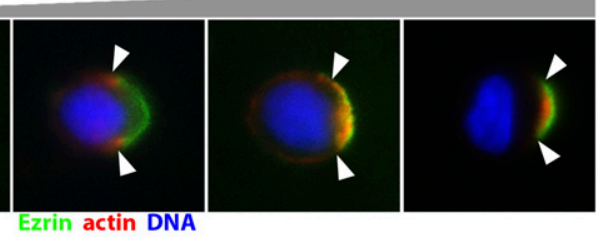

C

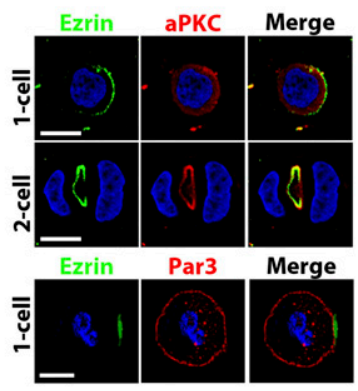

D

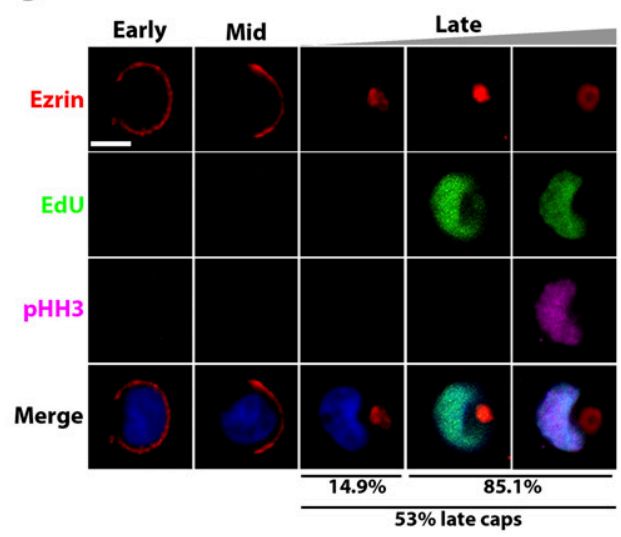

Figure 1. Restricted cortical distribution of Ezrin in single Caco2 cells. $(A)$ Ezrin localizes to the cleavage furrow and nascent apical lumen in developing Caco2 cysts. Single Caco2 cells were embedded in Matrigel for $16 \mathrm{~h}$ (two-cell stage) or $6 \mathrm{~d}$ (cysts) and stained for Ezrin (green), actin (red), and DNA (blue). Unless otherwise indicated, all images shown are single confocal sections through the middle of each structure. Corresponding differential interference contrast (DIC) images are also shown. (B) Cortical Ezrin is progressively restricted into a cap-like structure (arrowheads) that colocalizes with markedly enriched cortical actin in single Caco2 cells. Cells were stained as in $A$ and imaged using a wide-field fluorescence microscope. Images shown represent the stages of capping deduced from the analysis of hundreds of fixed samples processed at defined time points between 0 and $14 \mathrm{~h}$ after plating. $(C)$ Apical polarity proteins are not concentrated in the Ezrin cap. Embedded Caco2 cells were stained for Ezrin (green), DNA (blue), and aPKC or Par-3 (red). Apical polarity is initiated following the first cell division (aPKC, two-cell). $(D)$ The Ezrin cap forms prior to $\mathrm{S}$ phase. Embedded Caco2 cells were incubated with EdU for $14 \mathrm{~h}$ and stained for Ezrin (red), EdU (green), pHH3 (purple), and DNA (blue). Of the $\sim 53 \%$ of cells that had a mature Ezrin cap in this experiment, 85.1\% stained positively for EdU and/or $\mathrm{pHH} 3$, and $14.9 \%$ stained negatively for $\mathrm{EdU} / \mathrm{pHH} 3$. In contrast, cells with an immature Ezrin cap rarely stained positively for $\mathrm{EdU} / \mathrm{pHH} 3$. Bars, $10 \mu \mathrm{m}$. This figure is related to Supplemental Figure S1. formation is dependent on the integrity of the actin cytoskeleton. Treatment of cells with cytochalasin D, jasplakinolide, or latrunculin A-drugs that disrupt actin by different mechanisms - abolished cap formation in single cells; in contrast, cells treated with the microtubuledepolymerizing agent nocodazole formed caps normally (Fig. 2A). Polarization of the single-celled Caenorhabditis elegans oocyte is driven by actomyosin-powered cortical flow of membrane proteins (Munro et al. 2004); however, neither inhibitors of myosin II (blebbistatin) nor Rho kinase (Y27632), which acts upstream of myosin II, perturbed Ezrin cap formation (Fig. 2A).

The ERM proteins are activated by a phosphorylationmediated conformational change that unmasks the N-terminal four-point-one-ERM (FERM) and C-terminal actin-binding domains; phosphorylation of residues within the FERM and C-terminal domains may cooperate to effect and sustain ERM activation (Pearson et al. 2000; Yang and Hinds 2003). An antibody that specifically detects phosphorylation of the well-studied T567 C-terminal residue recognized cortical Ezrin during all stages of cap formation (Fig. 2B; data not shown). The Ste20 family kinases SLK, LOK, and MST4 can all phosphorylate this residue; in fact, it has been argued that SLK is necessary and sufficient for phosphorylation and activation of the single ERM Moesin in Drosophila melanogaster, while MST4-mediated phosphorylation of Ezrin is important for brush border formation in Caco2 cells (Hipfner et al. 2004; Carreno et al. 2008; Kunda et al. 2008; Belkina et al. 2009; ten Klooster et al. 2009; Gloerich et al. 2012). However, elimination of mammalian SLK, LOK, or MST4 did not reduce Ezrin C-terminal phosphorylation or perturb cap formation (Fig. 2C; Supplemental Fig. S2A-C).

The N-terminal residue T235 directly apposes T567 in crystal structures of self-associated ERMs and can be phosphorylated by the cyclin-dependent kinase CDK5 (Pearson et al. 2000; Yang and Hinds 2003). Indeed, treatment with the pan-CDK inhibitor roscovitine dramatically perturbed Ezrin cap formation and largely eliminated the cortical localization of Ezrin (Fig. 2D). The absence of $\mathrm{pHH} 3$-positive cells confirmed the activity of roscovitine in these experiments (Supplemental Fig. S2D). Moreover, elimination of the expression of CDK5 (which is inhibited by roscovitine) or its major activator, p35, also dramatically decreased the proportion of single cells with an Ezrin cap (Fig. 2E; Supplemental Fig. S2E). 
Hebert et al.
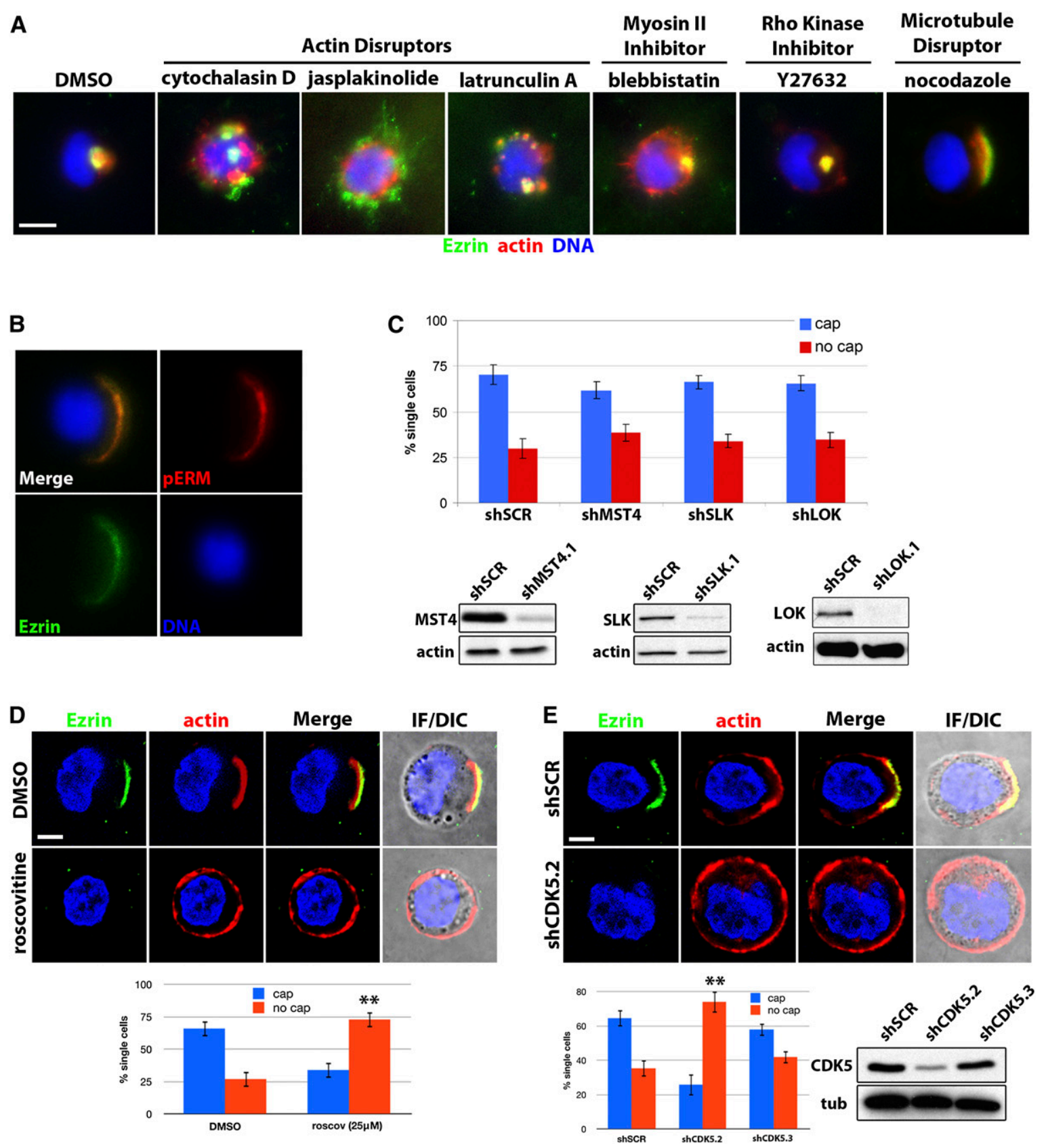

Figure 2. Regulation of Ezrin cap formation. $(A)$ Ezrin cap formation is dependent on actin. Single embedded Caco 2 cells were cultured with vehicle (DMSO), actin-disrupting compounds (cytochalasin D, jasplakinolide, or latrunculin A), myosin II inhibitors (blebbistatin), Rho kinase inhibitor (Y27632), or the microtubule-depolymerizing drug nocodazole and stained for Ezrin (green), actin (red), and DNA (blue). Note that the image of the blebbistatin-treated cell is intentionally overexposed to confirm blebbistatin activity. Cells were imaged using a wide-field fluorescence microscope. (B) The Ezrin cap contains active C-terminally phosphorylated ERMs (pERM). Single embedded Caco2 cells were fixed with TCA to preserve the pERM epitope and stained for Ezrin (green), pERM (red), and DNA (blue). (C) Neither MST4 nor the related kinases SLK and LOK are necessary for Ezrin cap formation. Cells infected with lentiviruses expressing control (scrambled; shSCR) or MST4, SLK, or LOK targeted shRNAs were subjected to immunoblotting analysis of Ezrin cap formation. $(D)$ The pan-CDK inhibitor roscovitine prevents cortical Ezrin localization and cap formation. Single embedded Caco2 cells were cultured with $25 \mu \mathrm{M}$ roscovitine for $14 \mathrm{~h}$, then stained for Ezrin (green), actin (red), and DNA (blue). (E) CDK5 is required for Ezrin cortical localization and cap formation. Cells were stably infected with lentiviruses expressing control (shSCR) or two short hairpins targeting CDK5 (shCDK5.2 and shCDK5.3). Most shCDK5.2-expressing cells do not form Ezrin caps, while shCDK5.3-expressing cells exhibit a mild defect in cap formation, consistent with the weak knockdown achieved with shCDK5.3. Values shown are mean \pm SEM. $\left.{ }^{\star \star}\right) P<0.01$. Bars, $10 \mu \mathrm{m}$. This figure is related to Supplemental Figure S2. 
Like those treated with roscovitine, the majority of single CDK5-deficient cells failed to concentrate Ezrin at the membrane at all. Unlike roscovitine-treated cells, however, CDK5-deficient cells progressed normally into S phase, indicating that Ezrin cap formation is not dependent on or required for S phase progression (data not shown). Notably, neither roscovitine treatment nor CDK5 deficiency obviously perturbed cortical actin itself (Fig. 2D,E), although we cannot rule out the possibility that other CDK5 targets contribute to Ezrin cap formation. Together, our data suggest that CDK5-mediated Ezrin activation is a prerequisite for the cell cycle-dependent reorganization of the cell cortex prior to mitosis.

\section{Ezrin cap formation is dependent on Merlin}

Substantial evidence suggests that the ERM proteins and Merlin share a functional and conserved relationship, but the nature of that relationship is obscure (McClatchey and Fehon 2009). We found that in cells forming an Ezrin cap, exogenous wild-type Merlin does not colocalize with Ezrin and instead decorates the entire cell cortex (Fig. 3A). In contrast, a mutant version of Merlin $\left(\mathrm{Nf} 2^{18-595}\right)$ that does not stably localize to the cortical cytoskeleton (Cole et al. 2008) remains cytoplasmic throughout Ezrin cap formation (Fig. 3A). In cysts, endogenous or exogenous wild-type Merlin concentrates along the apical and apical junctional region, where it overlaps with Ezrin (Supplemental Fig. S3A).

Strikingly, we found that elimination of endogenous NF2 expression completely prevented Ezrin cap formation (Fig. 3B). However, in contrast to roscovitine treatment or elimination of CDK5, loss of Merlin yielded either uniform cortical localization of Ezrin or the appearance of multiple cortical Ezrin patches, suggesting that rather than influencing Ezrin activation, Merlin normally functions to restrict the localization of active Ezrin at the membrane. In fact, re-expression of either wild-type or myristoylated, membrane-tethered Merlin $\left(\mathrm{NF}^{\mathrm{myr}}\right.$ ) rescued Ezrin cap formation (Fig. 3C). In contrast, Ezrin cap formation was not rescued by Nf2 $2^{18-595}$ (Fig. 3D). The N-terminal 17 amino acids of Merlin precede the FERM domain and are necessary for both localization to the cortical cytoskeleton and the direct association of Merlin with the actin-binding protein $\alpha$-catenin (Gladden et al. 2010). Notably, Ezrin neither has this $\mathrm{N}$-terminal motif nor interacts with $\alpha$-catenin (Gladden et al. 2010). The requirement of these residues for the cortical localization of Merlin in single Caco2 cells suggests that $\alpha$-catenin could link Merlin to the cortical cytoskeleton even in the absence of AJs. Indeed, Merlin fails to stably localize to the cortex of single cells in the absence of $\alpha$-catenin (Supplemental Fig. S3B). Moreover, Ezrin cap formation in single cells is completely dependent on $\alpha$-catenin (Fig. 3E; Supplemental Fig. S3C). These data identify a novel junctionindependent function for $\alpha$-catenin and suggest that the $\alpha$-catenin-dependent localization of Merlin to the cortex of single cells functions to restrict cortical Ezrin distribution prior to mitosis.
ERMs and Merlin are essential for centrosome positioning

As single Caco2 cells undergo mitosis in Matrigel, the cleavage furrow is converted to a junctional and then apical luminal surface, and subsequent mitotic spindles orient relative to that central apical lumen (Jaffe et al. 2008). It is not known whether a single cell actively orients the first mitotic spindle in the absence of an external cue or apical domain. The mitotic spindle forms after centrosome duplication and migration of one centrosome to the opposite pole (Nigg 2007). Centrosomes use astral microtubules to communicate with the cell cortex, but little is known about the molecular basis of this communication (Sandquist et al. 2011). During Ezrin cap formation, cells contain single centrosomes (Fig. 4A, left; Supplemental Fig. S4A); however, most cells harboring a mature Ezrin cap had undergone centrosome duplication, which occurs at the G1-S transition (Fig. 4A, middle; Supplemental Fig. S4A). We noted that prior to duplication, the single centrosome is always positioned beneath the Ezrin-decorated cortex, and centrosome duplication occurs immediately beneath the cap as soon as it is mature (Fig. 4A; Supplemental Fig. S4A). Subsequently, mitotic spindles always orient with one centrosome proximal to the Ezrin cap (Fig. 4B). During cytokinesis, Ezrin relocalizes to the cleavage furrow, from which the nascent apical lumen forms; during the ensuing interphase, centrosomes again localize in close apposition to Ezrin at the new apical surface (Fig. 4A, right). Thus, there is a tight correlation between the cortical distribution of Ezrin and the position of the centrosomes throughout the cell cycle.

To determine whether Ezrin provides a cortical cue for centrosome positioning, we examined the position of centrosomes in shNF2-expressing cells in which cortical Ezrin fails to be restricted to a single cap-like domain. In these cells, centrosomes were located in close proximity to the cell cortex and specifically to areas of the cortex that were decorated by ectopic Ezrin (Fig. 4C). In contrast, in cells that express shCDK5 and have no cortical Ezrin, centrosomes often failed to exhibit a clear cortical association (data not shown). Finally, we asked whether astral microtubules, which concentrate between the Ezrin cap and interphase centrosome (Supplemental Figure 4B), actually mediate communication between centrosomes and the Ezrin-decorated cortex. We found that although the microtubule-depolymerizing agent nocodazole did not prevent Ezrin cap formation, it completely eliminated the positioning of the centrosome beneath the Ezrin cap; nocodazole-treated cells, like shCDK5-expressing cells, exhibited a random and often noncortical localization of centrosomes (Fig. 4D). Finally, we found that microtubule-binding protein APC2, which is known to mediate communication between astral microtubules and cortical actin in Drosophila epithelia (McCartney et al. 2001), both localizes to the Ezrin cap (Supplemental Fig. S4C) and is required for the association between the Ezrin cap and centrosome (Fig. 4E). Together, these results suggest that Ezrin provides an intrinsic cortical cue for positioning 
A

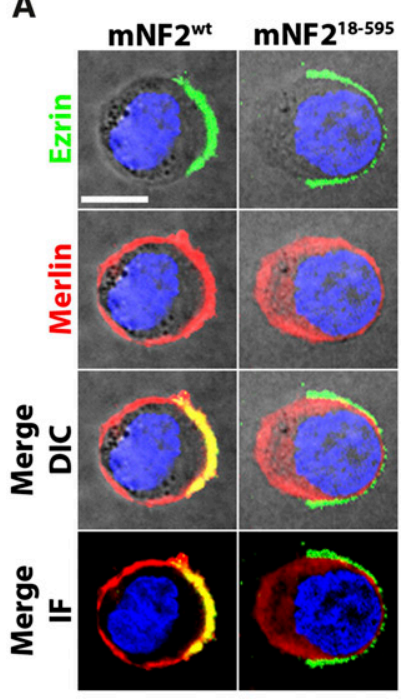

B

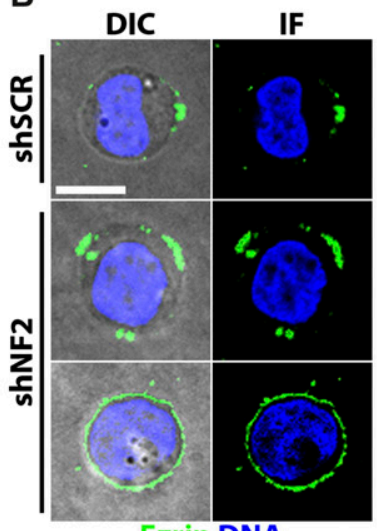

Ezrin DNA
C

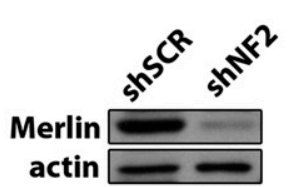

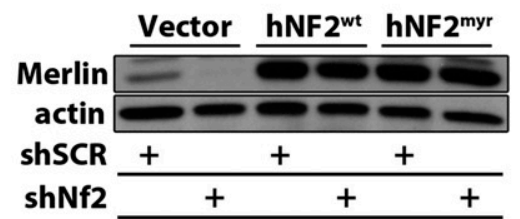

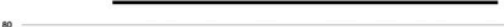

- i

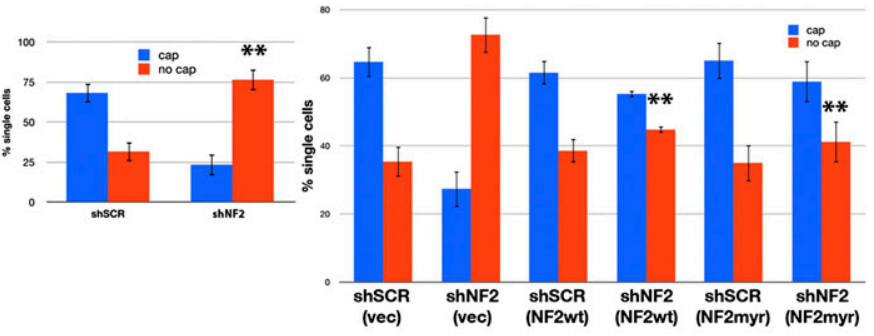

D

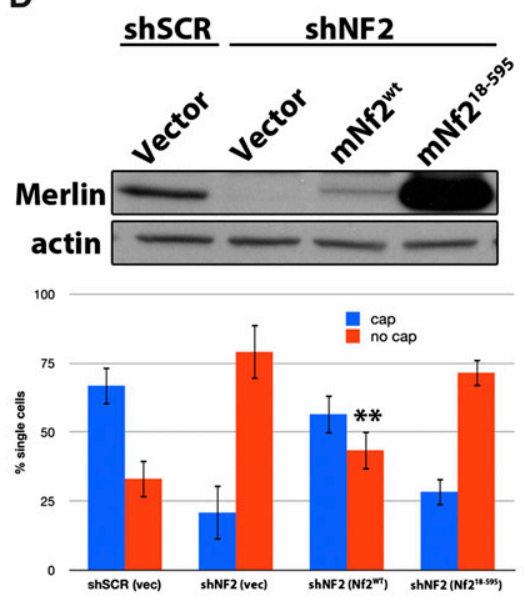

E

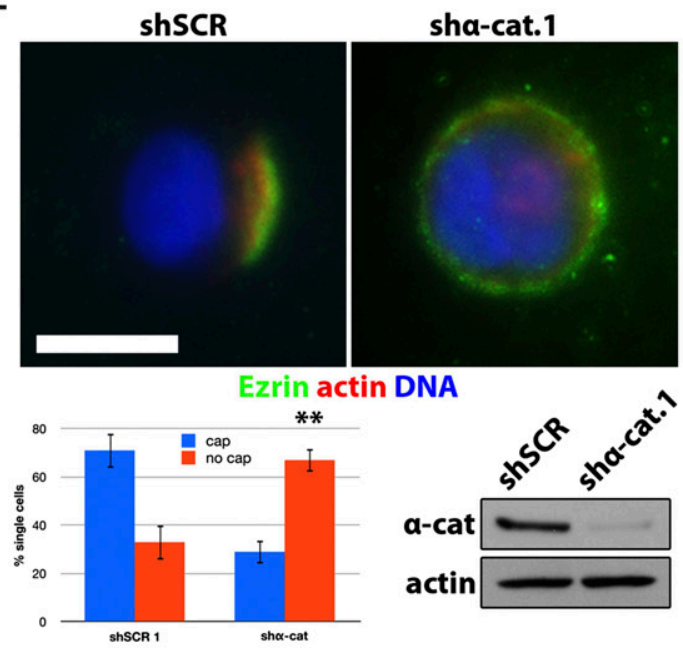

Figure 3. Merlin is required for Ezrin cap formation. (A) Merlin exhibits uniform cortical localization in cells harboring a mature Ezrin cap. Cells expressing Flag-tagged versions of wild-type mouse Merlin ( $\mathrm{mNf} 2^{\mathrm{wt}}$ ) or $\mathrm{mNf} 2^{18-595}$ were stained for endogenous Ezrin (green), Merlin (red), and DNA (blue). (B) Endogenous Merlin is required for Ezrin cap formation. Caco2 cells stably expressing control (shSCR) or NF2 targeted shRNAs (shNF2) were stained for Ezrin (green) and DNA (blue). The immunoblot confirms the loss of Merlin. (C) Ezrin capping was rescued by reintroduction of wild-type or membrane-tethered Merlin. CaCo2 cells stably expressing shSCR or shNF2 were infected with lentiviruses expressing shNF2-resistant wild-type (hNF2 ${ }^{\mathrm{wt}}$ ) or myristoylated (hNF2 ${ }^{\mathrm{myr}}$ ) human Merlin. The immunoblot confirms the loss of endogenous Merlin and expression of exogenous hNF2 ${ }^{\mathrm{wt}}$ and hNF2 ${ }^{\mathrm{myr}}$. $(D) \mathrm{mNf} 2^{18-595}$ did not rescue Ezrin cap formation. Cells stably expressing shSCR or shNF2 were infected with lentiviruses expressing mouse mNf2 ${ }^{\mathrm{wt}}$ or $\mathrm{mNf} 2^{18-595}$. The immunoblot confirms loss of Merlin and expression of exogenous $\mathrm{mNf} 2^{\mathrm{wt}}$ and $\mathrm{mNf} 2^{18-595}$. $(E) \alpha$-Catenin is required for Ezrin cap formation. Cells expressing control (shSCR) or $\alpha$-catenin targeted (sh $\alpha$-cat) shRNAs were stained for Ezrin (green), actin (red), and DNA (blue) and monitored for Ezrin cap formation. The immunoblot confirms the loss of $\alpha$-catenin protein. Values shown are mean \pm SEM. $\left(^{\star \star}\right) P<0.01$. Bars, $10 \mu \mathrm{m}$. This figure is related to Supplemental Figure S3.

the centrosome via astral microtubules and that cortical Merlin functions to restrict and position that cue.

\section{Coordination of cell cycle and polarity cues}

Although Ezrin cap formation is perturbed in shNF2expressing cells, some Ezrin does relocalize to the cleavage furrow and nascent lumen (Fig. 5A). However, in contrast to control cells, Ezrin was not restricted to the cleavage furrow and nascent apical lumen at the two-cell stage in the absence of Merlin and instead exhibited ectopic cortical localization (Fig. 5A). Centrosomes were also not restricted to the area beneath the nascent lumen and were instead often observed in proximity to ectopic cortical Ezrin (Fig. 5A). 


\section{A}

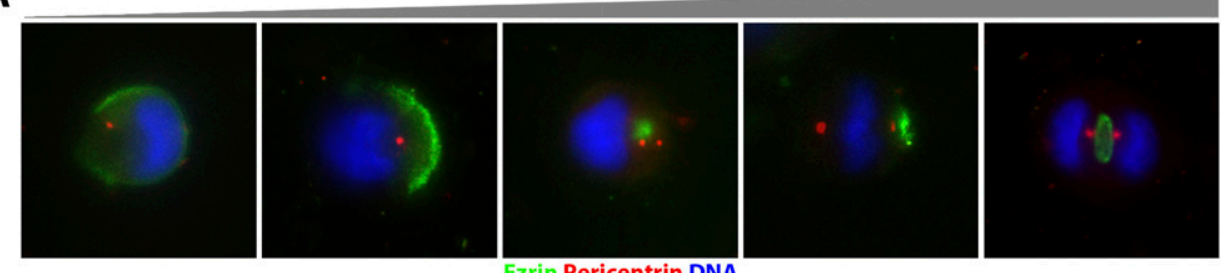

B

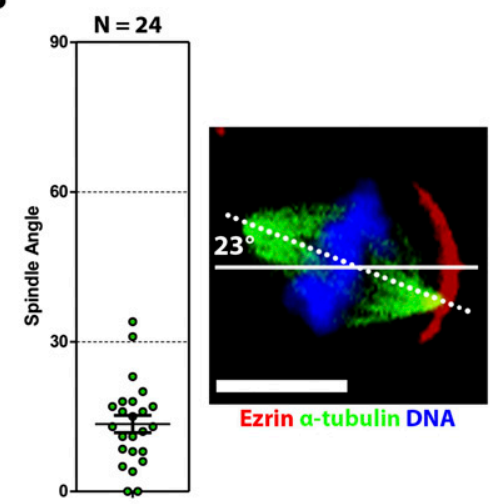

D

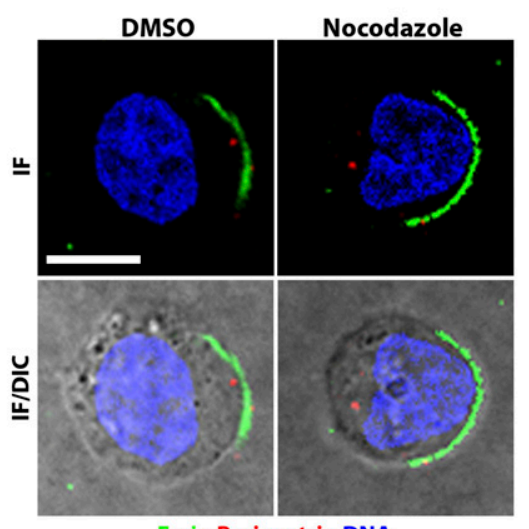

Ezrin Pericentrin DNA
C

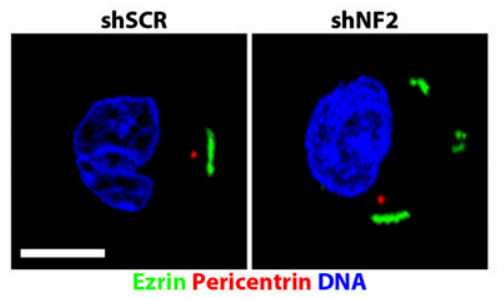

E

ShSCR

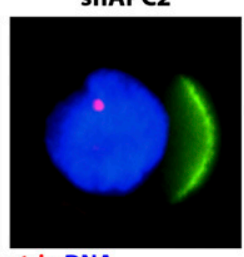

Ezrin Pericentrin DNA

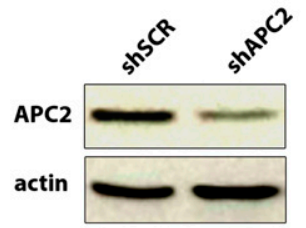

Figure 4. Cortical Ezrin controls centrosome position. $(A)$ Centrosome position correlates with cortical Ezrin. Cells were stained for Ezrin (green), Pericentrin (red), and DNA (blue) and imaged using a wide-field fluorescence microscope. Images shown represent the stages of capping deduced from the analysis of hundreds of fixed samples processed at defined time points between 0 and $17 \mathrm{~h}$ after plating. (B) In single cells, one spindle pole always localizes beneath the Ezrin cap. Cells were stained for Ezrin (red), $\alpha$-tubulin (green), and DNA (blue). The angles between the spindle axis (dashed line) and a line connecting the center of the Ezrin cap to the center of the spindle (solid line) were measured using Zen software and are depicted by the scatter plot at the left. $(C)$ Centrosomes localize beneath ectopic cortical Ezrin. Control (shSCR) or shNF2-expressing cells were stained for Ezrin (green), Pericentrin (red), and DNA (blue). (D) Microtubules are required for the positioning of centrosomes beneath cortical Ezrin. Cells were treated with vehicle (DMSO) or nocodazole $(20 \mu \mathrm{M})$ and stained for Ezrin (green), Pericentrin (red), or DNA (blue). (E) APC2 is required for the positioning of centrosomes beneath cortical Ezrin. Control (shSCR) or shAPC2-expressing cells were stained for Ezrin (green), Pericentrin (red), and DNA (blue). Identical results were obtained with a second shAPC2 hairpin (not shown). Bars, $10 \mu \mathrm{m}$. This figure is related to Supplemental Figure S4.

Ectopic Ezrin and defective centrosome positioning were associated with abnormal spindle orientation in cysts composed of two or more cells. In control cysts, as in MDCK cysts, centrosome duplication occurs apically and is followed by the migration of one centrosome to the opposite basolateral pole of the cell; this is followed by a $90^{\circ}$ rotation of the developing spindle such that cells divide symmetrically around the central lumen (Rodriguez-Fraticelli et al. 2010). In contrast, spindles in shNF2-expressing cells were randomly oriented at all 
A

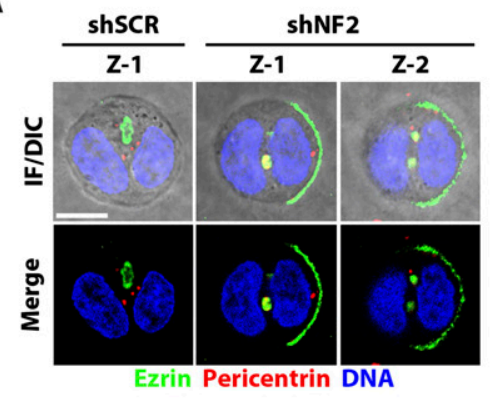

B
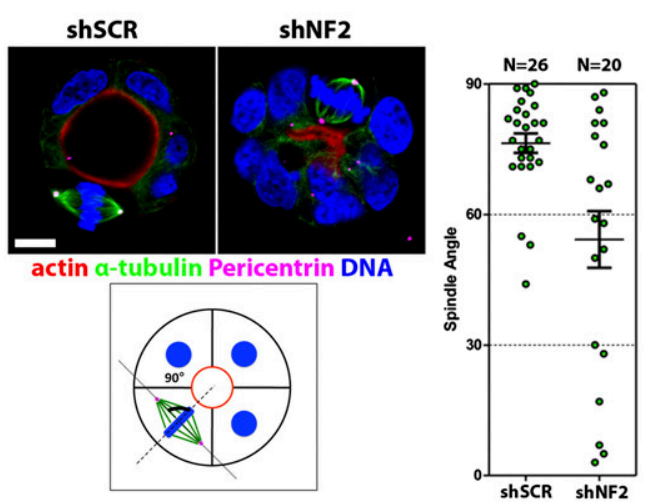

D
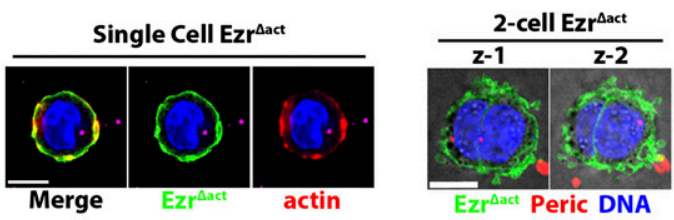
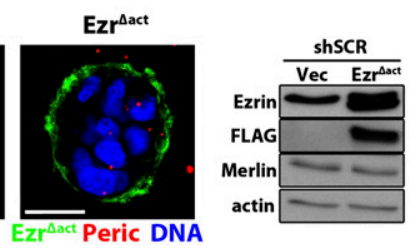

C

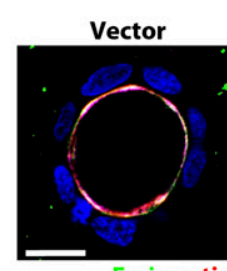

Ezrin actin aPKC DNA

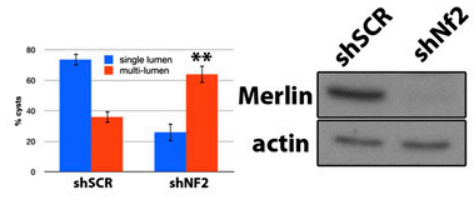

shNF2

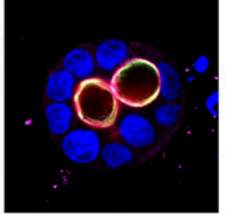

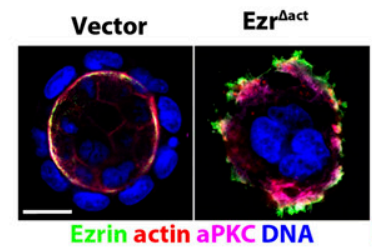

$\overline{\text { Ezrtact }}$ Peric DNA

E

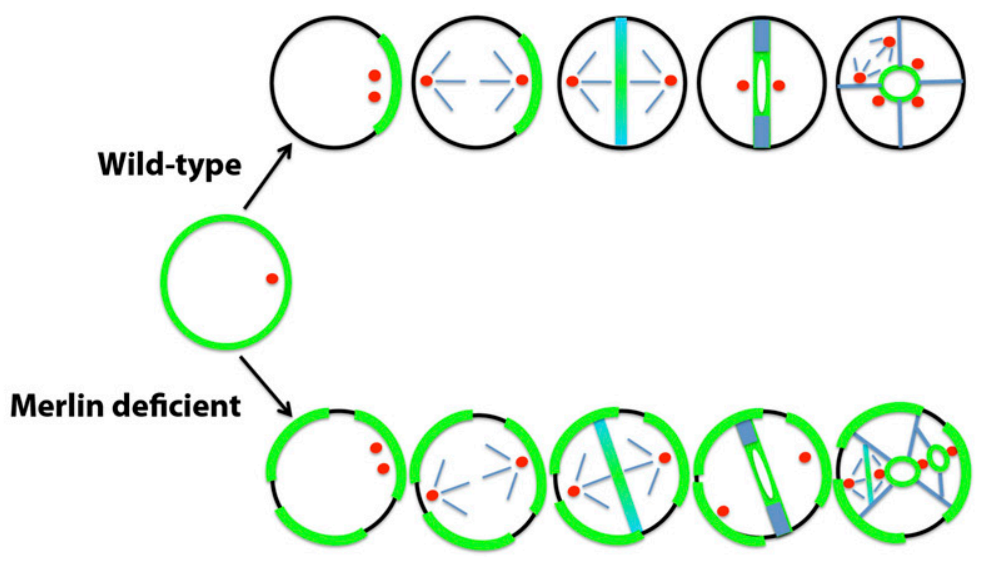

Figure 5. Merlin/ERMs are required for the development of cysts containing a single central lumen. (A) Ectopic Ezrin persists after the first cell division in developing shNF2-expressing cysts. Two-cell stage cysts expressing shSCR or shNF2 were stained for Ezrin (green), Pericentrin (red), and DNA (blue). In contrast to controls, Ezrin is not restricted to the cleavage furrow/nascent lumen in the absence of Merlin. Two optical Z sections are shown so that centrosomes from both cells can be seen. The cell on the left lacks ectopic Ezrin and the centrosome positions normally beneath the nascent lumen; the centrosome in the cell on the right is closely associated with ectopic cortical Ezrin. $(B)$ Ectopic cortical Ezrin is associated with aberrant spindle orientation. shSCR- and shNF2-expressing cells were stained for actin (red), $\alpha$-tubulin (green), Pericentrin (purple), and DNA (blue). (Schematic) Confocal images spanning both spindle poles were used to measure the angle between the spindle axis and a line connecting the apical surface of the cyst to the center of the spindle using Zen software. $(C)$ Loss of Merlin yields cysts with multiple lumens. Cysts were stained for Ezrin (green), actin (red), aPKC (purple), and DNA (blue). Control cells (shSCR) developed into cysts with a single lumen, but cells expressing shNF2 developed into cysts with multiple lumens. The immunoblot confirms the loss of Merlin expression. $(D)$ Dominant-negative Ezrin interferes with capping, centrosome positioning, and cyst formation. Cells infected with control or Flag-Ezr ${ }^{\Delta a c t}$ were cultured for $14 \mathrm{~h}$ (one- and twocell structures) or $6 \mathrm{~d}$ (cysts). Single cells were stained for Flag-Ezr ${ }^{\Delta a c t}$ (green), actin (red), Pericentrin (purple), and DNA (blue), while two-cell and cyst structures were stained for Ezrin (green; detects Ezrin and Flag-Ezr ${ }^{\text {act }}$ ) or Flag-Ezr ${ }^{\text {act }}$ (green), Pericentrin (red), and DNA (blue). Ezr ${ }^{\Delta \text { act }}$-expressing cysts fail to form lumens and localize Ezr ${ }^{\Delta \text { act }}$, actin and aPKC, which are normally apical, to the outer membrane that contacts the Matrigel. The immunoblot confirms the expression of Ezr ${ }^{\Delta \text { act }}$. Bars: one- to two-cell structures, $10 \mu m$; cysts, $20 \mu \mathrm{m}$. (E, top) Schematic showing how the restriction of cortical Ezrin (green) positions the interphase centrosome (red) and ensuing mitotic spindle in single control cells and in the derivative cyst with a single lumen. (Bottom) In the absence of Merlin, ectopic cortical Ezrin yields mispositioned centrosomes, misoriented spindles, and cysts with multiple lumens. Values shown are mean \pm SEM. $\left(^{\star \star}\right) P<0.01$. This figure is related to Supplemental Figure S5. 
times (Fig. 5B). Other studies have concluded that misorientation of the mitotic spindle leads to the formation of multiple lumens in 3D cyst models (Jaffe et al. 2008; Durgan et al. 2011; Rilla et al. 2011; Bray et al. 2012). Indeed, mature NF2-deficient cysts exhibit multiple lumens (Fig. 5C), a phenotype that can be rescued by exogenous expression of NF2 ${ }^{\mathrm{wt}}$ and $\mathrm{NF} 2^{\mathrm{myr}}$ but not by $\mathrm{Nf} 2^{18-595}$, which cannot associate with $\alpha$-catenin (Supplemental Fig. S5A,B). Elimination of $\alpha$-catenin expression also led to the formation of multiple lumens, consistent with the role of $\alpha$-catenin in cortically localizing Merlin (Supplemental Fig. S5C). Thus, Merlinmediated restriction of cortical Ezrin is critical for centrosome positioning and spindle orientation, which is in turn necessary for the formation of an epithelial cyst with a single central lumen (Fig. 5E).

Consistent with this model, elimination of ERM function via the expression of a well-characterized dominantnegative version of Ezrin (Ezr $\left.{ }^{\Delta \text { act }}\right)$ that can neither bind to nor stabilize actin or of shRNAs targeting both Ezrin and Radixin yielded loss of Ezrin capping and cysts that lacked lumens altogether (Fig. 5D; Supplemental Fig. S5D). This is consistent with the known function of Ezrin in establishing apical integrity and lumen formation in vivo (Saotome et al. 2004). Notably, actin and the apical marker aPKC were concentrated on the outer surface of ERM-deficient cysts apposed to the ECM, consistent with a reversal of polarity (Fig. 5D). However, centrosomes and spindles were randomly positioned even in these outer cells that form a pseudo-apical aPKCcontaining surface, consistent with the notion that active Ezrin itself is the essential cue for centrosome positioning (Fig. 5D; data not shown).

\section{Merlin cortically restricts Ezrin in vivo}

To determine whether the function of Merlin in cortically restricting Ezrin is essential in vivo, we examined the localization of Ezrin in the absence of Merlin in three different tissues (Fig. 6). In normal adult mouse skin, Ezrin is concentrated at the apical surface of certain basal cells, where they interface with overlying suprabasal cells; in contrast, Ezrin often prominently localizes to lateral boundaries between basal cells of the $N f 2$-deficient skin (Fig. 6A). Notably, $N f 2^{-1-}$ basal cells exhibit profound defects in spindle orientation and multilayering (Gladden et al. 2010). In kidney ductules, as in other epithelial monolayers, Ezrin is apically restricted (Ingraffea et al. 2002); however, loss of apically restricted Ezrin is one of the earliest detectable abnormalities in the Nf2deficient mouse kidney, which eventually harbors multiple adenomas that progress to renal carcinomas (Fig. 6B; Morris and McClatchey 2009). In fact, ectopic Ezrin localization is also associated with aberrant centrosome localization in the $N f 2^{-1-}$ kidney (Supplemental Fig. S6). Finally, although deletion of Nf2 in the adult mouse colon yielded no clear phenotype (data not shown), we found that the Nf2-deficient colonic epithelium exhibits defective repair after chemical damage. In contrast to the normal apical restriction of Ezrin, the pseudo-repaired

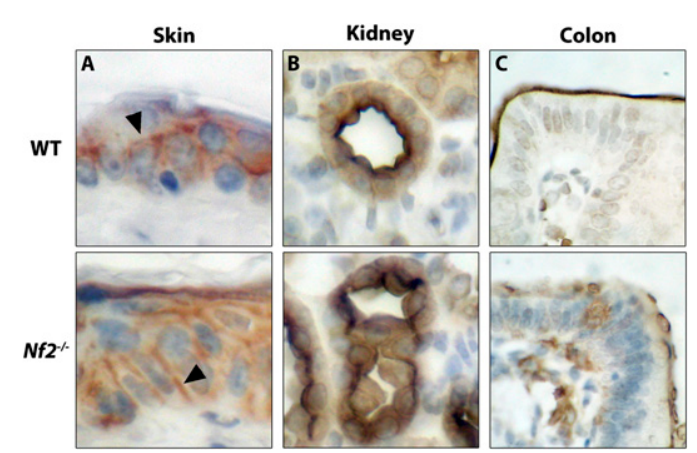

Figure 6. Ectopic Ezrin localization in Nf2-deficient tissues in vivo. $(A)$ In contrast to the adult mouse epidermis, where Ezrin normally concentrates at the apical surface of certain basal cells (arrowhead), Ezrin often prominently localizes to lateral boundaries between basal cells of the Nf2-deficient skin (arrowhead). $(B)$ Ezrin is apically restricted in wild-type proximal tubules of the kidney but is mislocalized prior to the formation of renal adenomas in the $N f 2^{-l-}$ kidney. $(C)$ After repair of chemically induced damage, Ezrin localization is restored to the apical surface in the wild-type but not in the $\mathrm{Nf}^{-/-}$colonic epithelium, which exhibits ectopic Ezrin localization and becomes progressively multilayered. This figure is related to Supplemental Figure S6.

$N f 2^{-1-}$ tissue exhibited ectopic Ezrin localization and became multilayered (Fig. 6C).

\section{Merlin/ERM proteins promote centrosome clustering}

Centrosome amplification is a feature of many cancer cells and can lead to the formation of multipolar spindles and chromosomal aneuploidy (Godinho et al. 2009). However, in many cancer cells, supernumerary centrosomes are clustered such that cells retain the ability to form bipolar spindles. The mechanisms by which centrosome clustering occurs are not well understood, but recent studies suggest a key role for the force-generating properties of the cortical actin cytoskeleton (Kwon et al. 2008). We hypothesized that a failure to restrict cortical Ezrin would prevent centrosome clustering and yield multipolar spindles. In fact, a significant fraction of Caco2 cells have supernumerary centrosomes but they cluster well, yielding predominantly bipolar spindles (Fig. 7A). However, shNF2-expressing Caco2 cells often exhibited defective centrosome clustering and multipolar spindles in $3 \mathrm{D}$ cultures and did so with even greater frequency in 2D cultures (Fig. 7A). To determine whether Merlin is required for centrosome clustering in other tumor cell types, we eliminated NF2 expression in BT549 mammary tumor cells that also harbor supernumerary centrosomes (Kwon et al. 2008); again, loss of Merlin prevented centrosome clustering and yielded a marked increase in multipolar spindle formation (Fig. 7B). Similar results were observed in U2OS osteosarcoma cells (Supplemental Fig. S7). Finally, we asked whether centrosome unclustering occurs in human NF2-deficient tumors, such as malignant mesotheliomas that frequently harbor homozygous NF2 mutation. We found that NF2deficient mesothelioma cells exhibited prominent cen- 
Hebert et al.

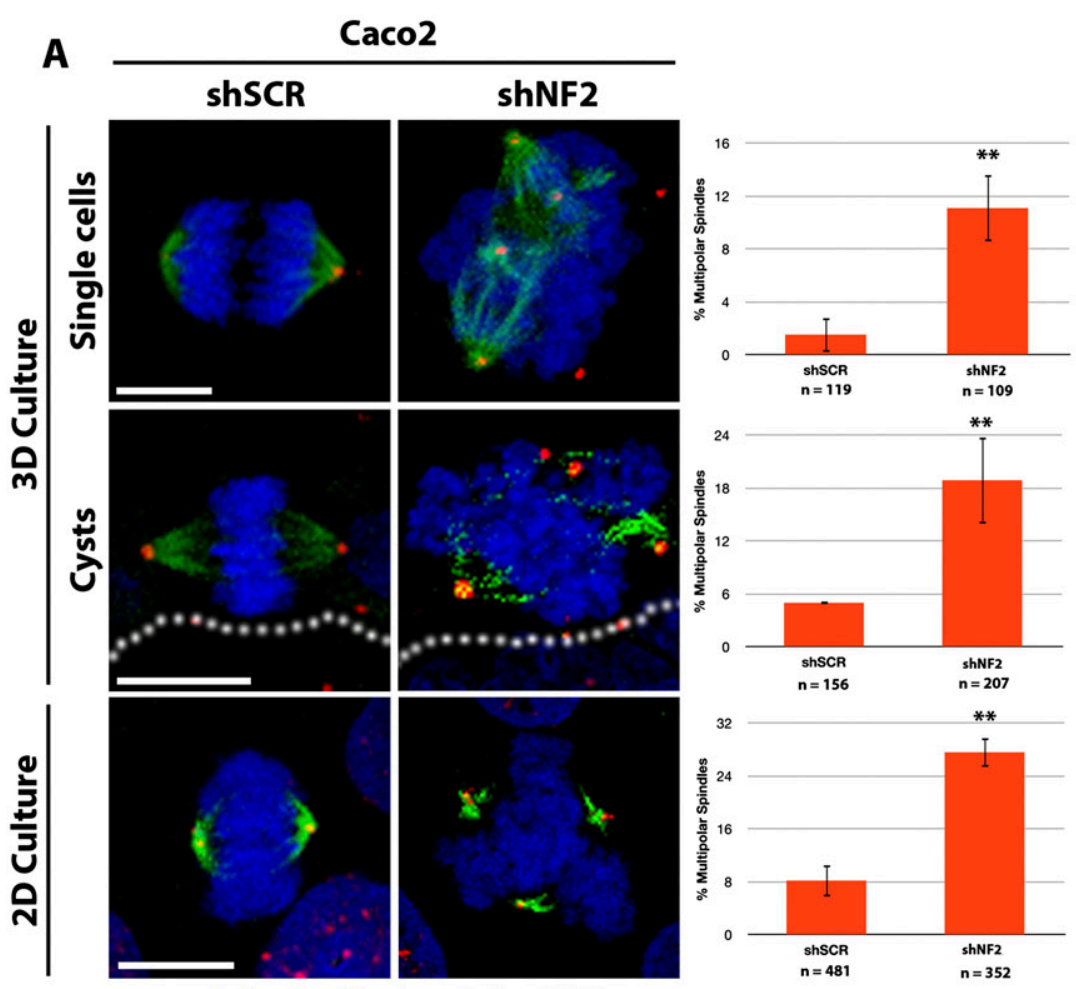

a-tubulin Pericentrin DNA
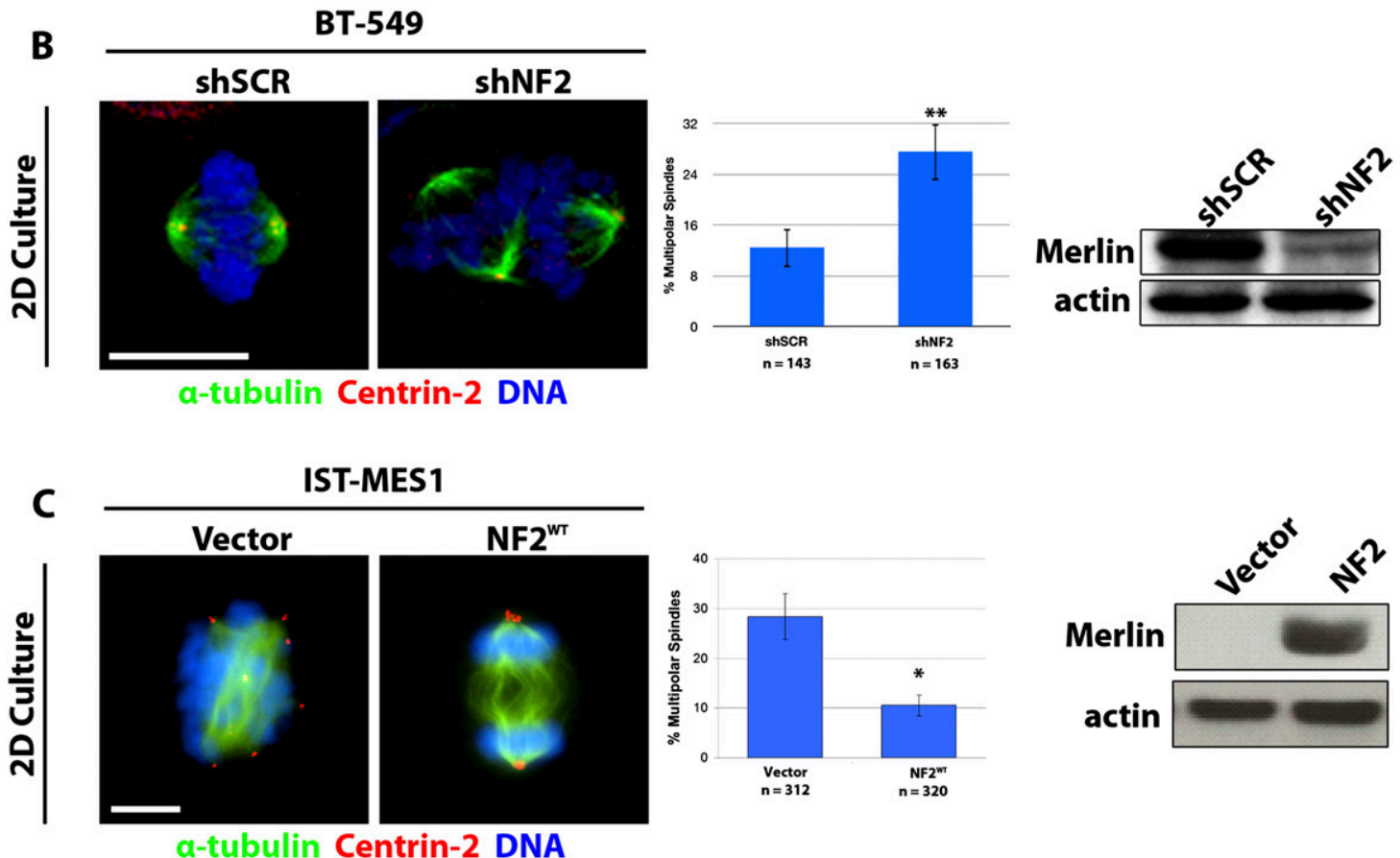

IST-MES1
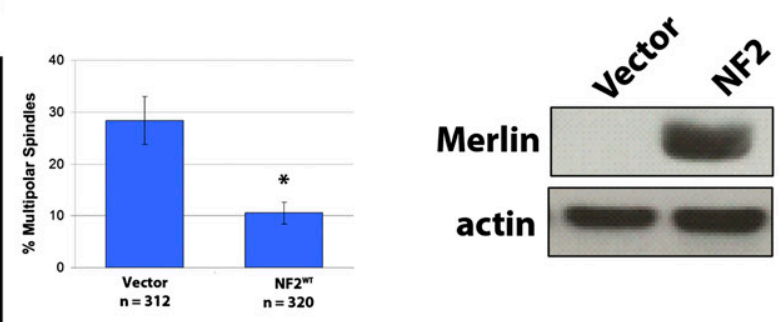

Figure 7. Loss of Merlin prevents centrosome clustering. $(A)$ Loss of Merlin yields multipolar spindles in Caco2 cells grown in 3D culture (top) or 2D culture (bottom). Cells were stained for $\alpha$-tubulin (green), Pericentrin (red), or DNA (blue). The dotted line marks the cyst apical surface. (B) Loss of Merlin yields multipolar spindles in BT-549 mammary tumor cells. BT-549 cells grown in 2D cultures were stained for $\alpha$-tubulin (green), Centrin-2 (red), and DNA (blue). (C) IST-MES1 human mesothelioma cells do not express full-length Merlin protein and exhibit frequent multipolar spindle formation; re-expression of full-length NF2 ${ }^{\text {wt }}$ but not the control vector significantly reduces multipolar spindle formation in these cells. For all experiments, centrosome clustering was also scored, with essentially identical results (not shown). Bars, $10 \mu \mathrm{m} . n=$ number of mitoses scored. Values shown are mean $\pm \mathrm{SEM}$. $\left(^{\star \star}\right) P<0.01$; $\left.{ }^{*}\right) P<0.05$. This figure is related to Supplemental Figure S7. 
trosome unclustering and multipolar spindles that were markedly inhibited by reintroduction of NF2 expression (Fig. 7C). Together, these data suggest that Merlin promotes centrosome clustering and prevents multipolar spindle formation by restricting the distribution of Ezrin in many cell types; they also suggest that defective centrosome clustering may contribute to the tumorigenic consequences of NF2 loss.

\section{Discussion}

These studies reveal that a fundamental activity of the tumor suppressor Merlin is to restrict the cortical distribution of Ezrin via a mechanism that requires the association of Merlin with $\alpha$-catenin at the cortex. This discovery in turn uncovered a previously unrecognized role for Ezrin in controlling centrosome position and provided mechanistic insight into both centrosome-tocortex communication and centrosome clustering. This work therefore emphasizes and expands the critical function of Merlin/ERM proteins as organizers of the cortex. As such, we provide new insight into how cortical polarity is achieved and used to build multicellular tissues and into how defective cortical organization contributes to tumorigenesis.

Our discovery of the cell cycle-mediated restriction of cortical Ezrin in single Caco2 cells reveals that cortical asymmetry can be intrinsically achieved in the absence of external cues and indicates that a key consequence of symmetry breaking is to organize the mechanical properties of the cell cortex. The observation that Merlin actively restricts the cortical activity of Ezrin suggests that the mechanical properties of the Ezrin- versus Merlin-decorated cortex are distinct. The ERMs interact directly with actin filaments via a conserved C-terminal actin-binding domain, but Merlin lacks this domain. Instead, Merlin can directly associate with $\alpha$-catenin, a core AJ component and actin-interacting protein (Gladden et al. 2010). We found that $\alpha$-catenin is necessary for the stable localization of Merlin to the cortical cytoskeleton in single Caco2 cells and that $\alpha$-catenin loss phenocopies Merlin deficiency in single cells and cysts, yielding ectopic cortical Ezrin and multiple lumens. Since $\alpha$-catenin can regulate actin cytoskeleton dynamics (Drees et al. 2005; Yamada et al. 2005; Benjamin et al. 2010), it is tempting to speculate that Merlin uses $\alpha$-catenin to modify cortical actin in a way that is distinct from that of Ezrin. Thus, we discovered a novel junction-independent-although perhaps not cadherin-independent (see Supplemental Fig. S1A)-function for $\alpha$-catenin in organizing the physical properties of the cell cortex and establishing cortical polarity.

The proximal function of temporally restricting Ezrin is to position the interphase centrosome. Astral microtubules connect centrosomes to the cell cortex and apply pulling forces to the cortical cytoskeleton during mitosis (Manneville and Etienne-Manneville 2006; Kunda and Baum 2009; Vaughan and Dawe 2010). Cortical actin patches may localize microtubule anchoring and/or motor proteins such as APC2 and dynein to counteract such forces (McCartney et al. 2001; Sandquist et al. 2011). Our findings are consistent with a model wherein the cell cycle-dependent restriction of Ezrin locally stabilizes actin, nucleating a physical platform that also contains APC2 for astral microtubule-mediated positioning of the interphase centrosome prior to spindle formation.

The cortical Ezrin cap that forms in single cells does not contain other polarity proteins and does not support the formation of microvilli. Polarity and adhesion proteins, along with Ezrin, are subsequently recruited to the nascent junction and apical lumen during or after cleavage furrow formation (Fig. 1C; Jaffe et al. 2008). In fact, Ezrin is also required for apical integrity and lumen formation in Caco2 cysts, as it is in vivo (Saotome et al. 2004). In the absence of ERM activity, the cleavage furrow is not converted into apical membrane; conversely, ectopic Ezrin is associated with the formation of ectopic lumens. Therefore, our data suggest that Ezrin is upstream of other polarity markers, a notion consistent with the identification of the ERM-interacting receptor gp135/podocalyxin as the earliest detectable apical marker during MDCK cyst formation (Bryant et al. 2010). Notably, forced activation of the LKB1 kinase can induce the formation of a domain containing apical polarity, junctional, and brush border proteins in single colonic or intestinal epithelial cells; in fact, MST4-induced Ezrin phosphorylation was implicated in brush border formation but not polarity in these studies (Baas et al. 2004; ten Klooster et al. 2009; Gloerich et al. 2012). However, knockdown of MST4 had no effect on Ezrin phosphorylation, capping, or cyst formation (Fig. 2C; Supplemental Fig $2 \mathrm{~A}$; data not shown). In fact, none of the candidate ERM C-terminal kinases that we tested were required for Ezrin phosphorylation or cap formation; instead, we found that CDK5 (which can phosphorylate the N-terminal Ezrin FERM domain) (Yang and Hinds 2003) or its obligate activator, p35, is required for Ezrin cap formation but not C-terminal Ezrin phosphorylation (data not shown). Perhaps activation of MST4 or other C-terminal kinases cooperate to convert the cell cycle-correlated Ezrin cap into a differentiated apical brush border. In fact, the redistribution of active Ezrin to the cleavage furrow and nascent lumen occurs in the absence of CDK5, suggesting that other Ezrin regulators drive this redistribution. Thus, Ezrin may provide the initial platform for assembling centrosome-positioning and/or polarity complexes, depending on the context. Merlin-mediated restriction of cortical Ezrin would then be central to the integration of temporal (cell cycle) and spatial (apical) cues during the organization and maintenance of multicellular structures.

From the two-cell stage on, the interphase centrosome localizes beneath the Ezrin-positive apical surface, as it does in many epithelial tissues; however, the spindle, either after or during its formation, rotates $90^{\circ}$ to effect symmetric division. This rotation may involve transient inactivation of Ezrin at the apical pole and/or the more dominant cortical force-generating activity of lateral AJs. The latter would fit well with studies of Drosophila neuroblast or germ cell division during which the AJ 
dominates over other cues to direct division orientation (Lu et al. 2001; Yamashita et al. 2010). In the absence of Merlin, Ezrin is not apically restricted, and interphase centrosomes localize near ectopic cortical Ezrin, leading to random spindle orientation and the formation of ectopic lumens, highlighting the dual function of Ezrin in positioning the centrosome and nucleating a bona fide apical domain during epithelial morphogenesis.

The failure to restrict the cortical distribution of Ezrin may contribute to the tumorigenic consequences of NF2 loss in several ways. First, defects in centrosome positioning and spindle orientation can yield defective epithelial homeostasis. Indeed, loss of Merlin yields ectopic Ezrin, defective spindle orientation, and multilayering of basal cells in mouse skin (Gladden et al. 2010). Similarly, ectopic Ezrin and centrosome localization precede the development of adenomas and, eventually, adenocarcinomas in the $\mathrm{Nf2^{-/- }}$ mouse kidney (Morris and McClatchey 2009). Alternatively, in cells with supernumerary centrosomes, aberrant centrosome clustering could affect genome stability (Kwon et al. 2008). For example, transient defects in centrosome clustering can promote chromosome missegregation and aneuploidy (Ganem et al. 2009). NF2 inactivation is found in an increasing number of sporadic malignant human cancers, including mesothelioma and renal adenocarcinoma, both of which are often aneuploid (Musti et al. 2006; Dalgliesh et al. 2010); in fact, we found that NF2-deficient mesothelioma cells exhibit defective centrosome clustering and multipolar spindle formation that is rescued by reexpression of NF2. Alternatively, loss of spindle pole clustering could decrease cell viability due to mitotic catastrophe (Ganem et al. 2009). Thus, in some contexts, loss of Merlin could actually favor tumor genome stability, as displayed by the benign tumors that NF2 patients predominantly develop. Finally, the local restriction of cortical Ezrin could contribute to the established functions of Merlin in controlling membrane receptor distribution and/or cell-cell junctions (Lallemand et al. 2003; Maitra et al. 2006; Curto et al. 2007; Benhamouche et al. 2010; Gladden et al. 2010). For example, the ability of Merlin to control the internalization of the epidermal growth factor receptor (EGFR) in a cortical cytoskeletondependent manner (Curto et al. 2007; Cole et al. 2008) could involve receptor-proximal restriction of the mechanical effects of Ezrin on cortical actin. Similarly, Merlin-mediated restriction of Ezrin to the apical domain could drive junctional maturation (Gladden et al. 2010). Key future goals will be to determine how these activities are coordinated and whether certain cell types or cellular contexts are differentially sensitive to the loss of specific Merlin activities.

\section{Materials and methods}

\section{Cell culture}

Human Caco2 cells (the Caco2 $2_{\mathrm{BBe}}$ subclone was used throughout; a gift from Wayne Lencer, Children's Hospital, Boston) were cultured in DMEM $/ 10 \%$ fetal bovine serum (FBS). For 3D cultures, cells were trypsinized, resuspended in culture medium, and passed through a $40-\mu \mathrm{m}$ filter to remove cell aggregates. Single-cell suspensions were spun at $4 \times 10^{3} \mathrm{RPM}$ for $1 \mathrm{~min}$ at $4^{\circ} \mathrm{C}$, then resuspended in ice-cold collagen/Matrigel $(1 \mathrm{mg} / \mathrm{mL}$ collagen I, 0.02 M HEPES/40\% Matrigel; BD Biosciences) to a concentration of $6 \times 10^{4}$ cells per milliliter, plated in an eightwell chamber slide, allowed to set for $30 \mathrm{~min}$ at $37^{\circ} \mathrm{C}$, and overlayed with medium. BT-549 and IST-MES1 cells (gifts from Cyril Benes, Massachusetts General Hospital Center for Molecular Therapeutics, Boston) were cultured in RPMI $/ 5 \%$ FBS and DMEM/F12/10\% FBS, respectively. The following pharmacological inhibitors were added directly to the medium of 3D cultures: $100 \mu \mathrm{M}$ blebbistatin, $1 \mu \mathrm{M}$ jasplakinolide, $20 \mu \mathrm{M}$ Y27632 (Calbiochem), $5 \mu \mathrm{M}$ cytochalasin D, $20 \mu \mathrm{M}$ nocodazole (Sigma), $25 \mu \mathrm{M}$ roscovitine (Biomol), and $2 \mu \mathrm{M}$ latrunculin A (Cayman). The Click-iT EdU cell proliferation assay (Invitrogen) was used to detect newly synthesized DNA.

\section{Immunofluorescence (IF) and microscopy}

Caco2 cells in 3D culture were fixed in $3.7 \%$ formaldehyde in cytoskeletal buffer (CB) [10 mM 2-( $N$-morpholino)-ethanesulfonic acid sodium salt (MES) at $\mathrm{pH} 6.1,138 \mathrm{mM} \mathrm{KCl}, 3 \mathrm{mM}$ $\mathrm{MgCl}_{2}, 2 \mathrm{mM}$ EGTA] for $20 \mathrm{~min}$ at room temperature, washed in PBS, and permeabilized for $20 \mathrm{~min}$ in $0.5 \%$ Triton X-100 in PBS. For Centrin-2 staining and astral microtubule visualization, cells were fixed in cold methanol instead of CB. Cultured cells and paraffin sections of adult wild-type and $\mathrm{Nf2} 2^{-1-}$ mouse kidney were blocked for $1 \mathrm{~h}$ in PBST/0.2\% Triton X-100/0.1\% BSA $/ 10 \%$ goat serum. Primary antibodies were diluted in block buffer and incubated overnight at room temperature. Cells were incubated with secondary antibodies, 4' $6^{\prime}$-diamidino-2-phenylindole (DAPI), and/or rhodamine-phalloidin for $1 \mathrm{~h}$. Labeled cells were visualized using a Nikon 90i fluorescence microscope or a Zeiss LSM510 laser scanning confocal microscope, and images were processed using Elements (Nikon) or Zen (Zeiss) software. For Merlin cortical localization, Caco2 cells were infected with hNF2 ${ }^{\text {wt }}$ and plated in $3 \mathrm{D}$ culture for $16 \mathrm{~h}$ at $37^{\circ} \mathrm{C}$. Cells were washed in $1 \%$ Triton X-100 lysis buffer for $10 \mathrm{~min}$, rinsed in PBS, and fixed for $20 \mathrm{~min}$ in $3.7 \%$ formaldehyde in CB. Cells were then stained for Merlin (NF2 sc332) and Ezrin, then visualized using a Zeiss LSM510 laser scanning confocal microscope.

\section{Plasmids}

C-terminal myc epitope tags on hNF2 ${ }^{\text {wt }}$ and hNF2 ${ }^{\text {myr }}$ (gifts from Helen Morrison, Leibniz Institute, Germany) were removed by $\mathrm{PCR}$, and a silent mutation in hNF2 ${ }^{\mathrm{wt}}$ and $\mathrm{hNF} 2^{\mathrm{myr}}$ was introduced by site-directed mutagenesis to render these constructs resistant to shNF2 (details are in the Supplemental Material). $\mathrm{N}$-terminal Flag epitope tags were added onto $\mathrm{mNf2}{ }^{\mathrm{wt}}$ and $\mathrm{mNf} 2^{18-595}$ by cloning into the pFLEX vector. Dominant-negative ERM (Ezr ${ }^{\Delta a c t}$ ) was a gift from Rick Fehon (University of Chicago). Venus-tagged Par3 was a gift from Ian Macara (University of Virginia). All constructs were subcloned into the pCSC-SP-PW (pBOB) mammalian lentiviral expression vector.

\section{$\operatorname{shRNA}$}

Lentiviral shRNA constructs targeting human MST4, $\alpha$-E-catenin, SLK, LOK, APC2, Ezrin, and Radixin were purchased from Open Biosystems. Specificity was determined by Western blotting, and constructs that most efficiently targeted protein expression were used (details are in the Supplemental Material). The short hairpins targeting CDK5 and p35 were gifts from Phil 
Hinds (Tufts University). Scrambled control (shSCR) and NF2 targeting shRNA constructs were gifts from Marianne James (Massachusetts General Hospital).

\section{Lentivirus production}

Lentiviruses expressing shRNAs were generated by cotransfecting $293 \mathrm{~T}$ cells with shRNA constructs together with the packaging vectors $\triangle \mathrm{VPR}$ and VSVG (Fugene). Lentiviruses derived from $\mathrm{pBOB}$ constructs were generated similarly using the packaging vectors psPAX and pMD2.G (Fugene). Twenty-four hours post-infection, cells were selected with fresh medium containing $7 \mu \mathrm{g} / \mathrm{mL}$ puromycin for $48 \mathrm{~h}$ and plated in $2 \mathrm{D}$ or $3 \mathrm{D}$ culture. Caco2 cells stably expressing shSCR and shNF2 were subjected to Western blotting analysis to monitor NF2 levels in each experiment.

\section{Measurement of spindle angles}

Confocal images spanning both spindle poles of metaphase cells were taken. In single cells, the angle between the spindle axis and a line connecting the center of the Ezrin cap to the center of the spindle was measured (Fig. 4B). In structures with two or more cells, the angle between the spindle axis and a line connecting the center of the apical surface to the center of the spindle was measured (Fig. 5B). Axes were drawn and spindle angles were measured using Zen software.

\section{Antibodies}

Primary antibodies for IF and/or Western blotting were from Santa Cruz Biotechnology (NF2 sc332 1:100 for IF and 1:1000 for Western blotting, aPKC sc-216 1:200 for IF, CDK5 sc6247 1:1000 for Western blotting, and p35 sc820 1:1000 for Western blotting), Cell Signaling Technology (ERM 3142 1:1000 for Western blotting, phospho-ERM 3141 1:100 for IF, and pHH3 9701 1:200 for IF), Zymed ( $\alpha$-catenin 7A4 1:1000 for Western blotting), Sigma (Actin A3853 1:2000 for Western blotting, Flag M2 F1804 1:100 for IF and 1:1000 for Western blotting, and Flag F7425 1:100 for IF and 1:1000 for Western blotting), Epitomics (MST4 2049-1 1:1000 for Western blotting), Abcam (Pericentrin ab4448 1:1000 for IF, and APC2 ab113370 1:1000 for IF and 1:5000 for Western blotting), Bethyl Laboratories (SLK BL1917 1:500 for Western blotting, and LOK A300-400A 1:5000 for Western blotting), and BD Transduction Laboratories (E-cadherin 610182 at 1:100 for IF). For IF, the following secondary antibodies were used at 1:200: anti-rabbit or anti-mouse Alexa Fluor 488 (Invitrogen) and anti-rabbit or anti-mouse Cy3 or Cy5 (Jackson ImmunoResearch). Filamentous actin was labeled with rhodamine phalloidin (Invitrogen), and nuclei were labeled with DAPI.

\section{Western blotting}

Cells were lysed using RIPA lysis buffer $(50 \mathrm{mM}$ Tris at $\mathrm{pH}$ 7.4, $1 \%$ Triton X-100, $1 \%$ SDS, $0.5 \%$ sodium deoxycholate, $150 \mathrm{mM}$ $\mathrm{NaCl}, 1 \mathrm{mM}$ EDTA, $1 \mathrm{mM}$ EGTA, $1 \mathrm{mM}$ PMSF, $1 \mathrm{mM} \mathrm{Na}_{3} \mathrm{VO}_{4}$, $10 \mathrm{mM}$ sodium fluoride, $10 \mathrm{mM} \beta$-glycerophosphate, $1 \mathrm{mg} / \mathrm{mL}$ aprotinin, $1 \mathrm{mg} / \mathrm{mL}$ leupeptin) followed by brief sonication. Cell debris was cleared by centrifugation $(14,000 \mathrm{rpm}$ for $10 \mathrm{~min}$ at $4^{\circ} \mathrm{C}$ ), and lysates were quantitated by detergent-compatible protein assay (Bio-Rad), separated by SDS-PAGE, and transferred to PVDF. Membranes were blocked in 5\% milk and incubated with primary antibody for $1 \mathrm{~h}$ at room temperature or overnight at $4^{\circ} \mathrm{C}$ in $1 \%$ milk, and then with anti-mouse or anti-rabbit horseradish peroxidase-conjugated secondary antibodies (1:5000; Amersham).

\section{Centrosome clustering}

Caco2 and BT-549 cells were infected with lentiviruses expressing scrambled control (shSCR) or NF2 targeting (shNF2) short hairpins. Cells were then transferred to medium containing $7 \mu \mathrm{g} /$ $\mathrm{mL}$ puromycin for $48 \mathrm{~h}$ and plated on glass coverslips before fixing in $3.7 \%$ formaldehyde in CB. Cells were stained for $\alpha$-tubulin, Centrin-2, and DNA. Mitotic cells were scored for clustered versus unclustered centrosomes or multipolar spindles using a Zeiss LSM510 laser scanning confocal microscope.

\section{Statistics}

Throughout, data from at least three independent experiments were pooled and expressed as mean \pm SEM. Values were compared by two-tailed Student's $t$-test, with statistical significance of $P<0.01\left(^{\star \star}\right)$ or $P<0.05\left(^{\star}\right)$ indicated.

\section{Immunohistochemistry}

Paraffin sections of adult wild-type and $\mathrm{Nf2}^{-/-}$mouse epidermis and kidney (K14-Cre;Nf2 $2^{\text {lox/lox }}$ and Vil-Cre;Nf2 $2^{\text {lox/lox }}$, respectively) were stained for total Ezrin and counterstained with hematoxylin. For chemically induced colonic damage, Vil$C r e^{E R T 2} ; N f 2^{\text {lox } / l o x}$ mice (Giovannini et al. 2000; el Marjou et al. 2004) were treated with $2 \mathrm{mg}$ of tamoxifen or DMSO for $5 \mathrm{~d}$ to delete $\mathrm{Nf2}$ in the intestinal/colonic epithelium; $18 \mathrm{~d}$ later, the mice were treated with $2.5 \%$ dextran sulfate sodium (DSS) ad libitum in the drinking water for $5 \mathrm{~d}$ to induce colonic epithelial damage. Colonic tissue was harvested, paraffin-embedded, and sectioned for immunohistochemical localization of Ezrin.

\section{Acknowledgments}

We are grateful to Amity Manning, Nick Dyson, David Pellman, Spyros Artavanis-Tsakonas, and Othon Iliopoulos for thoughtful comments regarding this manuscript, and to members of the McClatchey laboratory for many fruitful discussions. We thank Sylvie Robine for Vil-Cre $e^{E R T 2}$ transgenic mice, and Marco Giovannini for $N f 2^{l o x / l o x}$ mice. We thank Cyril Benes, Rick Fehon, Phil Hinds, Marianne James, Wayne Lencer, Ian Macara, and Helen Morrison for reagents. These studies were supported by National Institutes of Health Grants (R01GM087558 and R01CA113733) and an MGH Research Scholars Award to A.I.M.

\section{References}

Algrain M, Turunen O, Vaheri A, Louvard D, Arpin M. 1993. Ezrin contains cytoskeleton and membrane binding domains accounting for its proposed role as a membrane-cytoskeletal linker. J Cell Biol 120: 129-139.

Baas AF, Kuipers J, van der Wel NN, Batlle E, Koerten HK, Peters PJ, Clevers HC. 2004. Complete polarization of single intestinal epithelial cells upon activation of LKB1 by STRAD. Cell 116: 457-466.

Belkina NV, Liu Y, Hao JJ, Karasuyama H, Shaw S. 2009. LOK is a major ERM kinase in resting lymphocytes and regulates cytoskeletal rearrangement through ERM phosphorylation. Proc Natl Acad Sci 106: 4707-4712.

Benhamouche S, Curto M, Saotome I, Gladden AB, Liu $\mathrm{CH}$, Giovannini M, McClatchey AI. 2010. Nf2/Merlin controls progenitor homeostasis and tumorigenesis in the liver. Genes Dev 24: 1718-1730.

Benjamin JM, Kwiatkowski AV, Yang C, Korobova F, Pokutta S, Svitkina T, Weis WI, Nelson WJ. 2010. $\alpha$ E-catenin regulates 
actin dynamics independently of cadherin-mediated cell-cell adhesion. J Cell Biol 189: 339-352.

Bettencourt-Dias M, Hildebrandt F, Pellman D, Woods G, Godinho SA. 2011. Centrosomes and cilia in human disease. Trends Genet 27: 307-315.

Bray K, Brakebusch C, Vargo-Gogola T. 2012. The Rho GTPase Cdc42 is required for primary mammary epithelial cell morphogenesis in vitro. Small GTPases 2: 247-258.

Bryant DM, Datta A, Rodríguez-Fraticelli AE, Peränen J, MartínBelmonte F, Mostov KE. 2010. A molecular network for de novo generation of the apical surface and lumen. Nat Cell Biol 12: $1035-1045$.

Carreno S, Kouranti I, Glusman ES, Fuller MT, Echard A, Payre F. 2008. Moesin and its activating kinase Slik are required for cortical stability and microtubule organization in mitotic cells. J Cell Biol 180: 739-746.

Charras GT, Hu CK, Coughlin M, Mitchison TJ. 2006. Reassembly of contractile actin cortex in cell blebs. I Cell Biol 175: 477-490.

Cole BK, Curto M, Chan AW, McClatchey AI. 2008. Localization to the cortical cytoskeleton is necessary for Nf2/merlindependent epidermal growth factor receptor silencing. Mol Cell Biol 28: 1274-1284.

Curto M, Cole BK, Lallemand D, Liu CH, McClatchey AI. 2007. Contact-dependent inhibition of EGFR signaling by Nf2/ Merlin. J Cell Biol 177: 893-903.

Dalgliesh GL, Furge K, Greenman C, Chen L, Bignell G, Butler A, Davies H, Edkins S, Hardy C, Latimer C, et al. 2010. Systematic sequencing of renal carcinoma reveals inactivation of histone modifying genes. Nature 463: 360-363.

Drees F, Pokutta S, Yamada S, Nelson WJ, Weis WI. 2005. $\alpha$-Catenin is a molecular switch that binds E-cadherin$\beta$-catenin and regulates actin-filament assembly. Cell 123: 903-915.

Durgan J, Kaji N, Jin D, Hall A. 2011. Par6B and atypical PKC regulate mitotic spindle orientation during epithelial morphogenesis. I Biol Chem 286: 12461-12474.

el Marjou F, Janssen KP, Chang BH, Li M, Hindie V, Chan L, Louvard D, Chambon P, Metzger D, Robine S. 2004. Tissuespecific and inducible Cre-mediated recombination in the gut epithelium. Genesis 39: 186-193.

Fehon RG, McClatchey AI, Bretscher A. 2010. Organizing the cell cortex: The role of ERM proteins. Nat Rev Mol Cell Biol 11: $276-287$.

Ganem NJ, Godinho SA, Pellman D. 2009. A mechanism linking extra centrosomes to chromosomal instability. Nature 460: $278-282$.

Giovannini M, Robanus-Maandag E, van der Valk M, NiwaKawakita M, Abramowski V, Goutebroze L, Woodruff JM, Berns A, Thomas G. 2000. Conditional biallelic Nf2 mutation in the mouse promotes manifestations of human neurofibromatosis type 2. Genes Dev 14: 1617-1630.

Gladden AB, Hebert AM, Schneeberger EE, McClatchey AI. 2010. The NF2 tumor suppressor, Merlin, regulates epidermal development through the establishment of a junctional polarity complex. Dev Cell 19: 727-739.

Gloerich M, ten Klooster JP, Vliem MJ, Koorman T, Zwartkruis FJ, Clevers H, Bos JL. 2012. Rap2A links intestinal cell polarity to brush border formation. Nat Cell Biol 14: 793801

Gobel V, Barrett PL, Hall DH, Fleming JT. 2004. Lumen morphogenesis in $C$. elegans requires the membrane-cytoskeleton linker erm-1. Dev Cell 6: 865-873.

Godinho SA, Kwon M, Pellman D. 2009. Centrosomes and cancer: How cancer cells divide with too many centrosomes. Cancer Metastasis Rev 28: 85-98.
Hipfner DR, Keller N, Cohen SM. 2004. Slik Sterile-20 kinase regulates Moesin activity to promote epithelial integrity during tissue growth. Genes Dev 18: 2243-2248.

Ingraffea J, Reczek D, Bretscher A. 2002. Distinct cell typespecific expression of scaffolding proteins EBP50 and E3KARP: EBP50 is generally expressed with ezrin in specific epithelial, whereas E3KARP is not. Eur J Cell Biol 81: 61-68.

Jaffe AB, Kaji N, Durgan J, Hall A. 2008. Cdc42 controls spindle orientation to position the apical surface during epithelial morphogenesis. J Cell Biol 183: 625-633.

Kunda P, Baum B. 2009. The actin cytoskeleton in spindle assembly and positioning. Trends Cell Biol 19: 174-179.

Kunda P, Pelling AE, Liu T, Baum B. 2008. Moesin controls cortical rigidity, cell rounding, and spindle morphogenesis during mitosis. Curr Biol 18: 91-101.

Kwon M, Godinho SA, Chandhok NS, Ganem NJ, Azioune A, Thery M, Pellman D. 2008. Mechanisms to suppress multipolar divisions in cancer cells with extra centrosomes. Genes Dev 22: 2189-2203.

LaJeunesse DR, McCartney BM, Fehon RG. 1998. Structural analysis of Drosophila merlin reveals functional domains important for growth control and subcellular localization. J Cell Biol 141: 1589-1599.

Lallemand D, Curto M, Saotome I, Giovannini M, McClatchey AI. 2003. NF2 deficiency promotes tumorigenesis and metastasis by destabilizing adherens junctions. Genes Dev 17: 1090-1100.

Lallemand D, Manent J, Couvelard A, Watilliaux A, Siena M, Chareyre F, Lampin A, Niwa-Kawakita M, Kalamarides M, Giovannini M. 2009. Merlin regulates transmembrane receptor accumulation and signaling at the plasma membrane in primary mouse Schwann cells and in human schwannomas. Oncogene 28: 854-865.

Lu B, Roegiers F, Jan LY, Jan YN. 2001. Adherens junctions inhibit asymmetric division in the Drosophila epithelium. Nature 409: 522-525.

Luxenburg C, Pasolli HA, Williams SE, Fuchs E. 2011. Developmental roles for Srf, cortical cytoskeleton and cell shape in epidermal spindle orientation. Nat Cell Biol 13: 203-214.

Macara IG, Mili S. 2008. Polarity and differential inheritanceuniversal attributes of life? Cell 135: 801-812.

Maitra S, Kulikauskas RM, Gavilan H, Fehon RG. 2006. The tumor suppressors Merlin and expanded function cooperatively to modulate receptor endocytosis and signaling. Curr Biol 16: 702-709.

Manneville JB, Etienne-Manneville S. 2006. Positioning centrosomes and spindle poles: Looking at the periphery to find the centre. Biol Cell 98: 557-565.

McCartney BM, McEwen DG, Grevengoed E, Maddox P, Bejsovec A, Peifer M. 2001. Drosophila APC2 and Armadillo participate in tethering mitotic spindles to cortical actin. Nat Cell Biol 3: 933-938.

McClatchey AI, Fehon RG. 2009. Merlin and the ERM proteins-regulators of receptor distribution and signaling at the cell cortex. Trends Cell Biol 19: 198-206.

McClatchey AI, Saotome I, Mercer K, Crowley D, Gusella JF, Bronson RT, Jacks T. 1998. Mice heterozygous for a mutation at the Nf2 tumor suppressor locus develop a range of highly metastatic tumors. Genes Dev 12: 1121-1133.

Morin X, Bellaiche Y. 2011. Mitotic spindle orientation in asymmetric and symmetric cell divisions during animal development. Dev Cell 21: 102-119.

Morris ZS, McClatchey AI. 2009. Aberrant epithelial morphology and persistent epidermal growth factor receptor signaling in a mouse model of renal carcinoma. Proc Natl Acad Sci 106: $9767-9772$. 
Munro E, Nance J, Priess JR. 2004. Cortical flows powered by asymmetrical contraction transport PAR proteins to establish and maintain anterior-posterior polarity in the early $C$. elegans embryo. Dev Cell 7: 413-424.

Musti M, Kettunen E, Dragonieri S, Lindholm P, Cavone D, Serio G, Knuutila S. 2006. Cytogenetic and molecular genetic changes in malignant mesothelioma. Cancer Genet Cytogenet 170: 9-15.

Nigg EA. 2007. Centrosome duplication: Of rules and licenses. Trends Cell Biol 17: 215-221.

Pearson MA, Reczek D, Bretscher A, Karplus PA. 2000. Structure of the ERM protein moesin reveals the FERM domain fold masked by an extended actin binding tail domain. Cell 101: 259-270.

Pereira G, Yamashita YM. 2011. Fly meets yeast: Checking the correct orientation of cell division. Trends Cell Biol 21: 526533.

Pilot F, Philippe JM, Lemmers C, Lecuit T. 2006. Spatial control of actin organization at adherens junctions by a synaptotagmin-like protein Btsz. Nature 442: 580-584.

Rauzi M, Lenne PF. 2011. Cortical forces in cell shape changes and tissue morphogenesis. Curr Top Dev Biol 95: 93-144.

Rilla K, Pasonen-Seppanen S, Karna R, Karjalainen HM, Torronen $\mathrm{K}$, Koistinen V, Tammi MI, Tammi RH, Teravainen $\mathrm{T}$, Manninen A. 2011. HAS3-induced accumulation of hyaluronan in 3D MDCK cultures results in mitotic spindle misorientation and disturbed organization of epithelium. Histochem Cell Biol 137: 153-164.

Rodriguez-Fraticelli AE, Vergarajauregui S, Eastburn DI, Datta A, Alonso MA, Mostov K, Martin-Belmonte F. 2010. The Cdc42 GEF Intersectin 2 controls mitotic spindle orientation to form the lumen during epithelial morphogenesis. I Cell Biol 189: 725-738.

Rouleau GA, Merel P, Lutchman M, Sanson M, Zucman J, Marineau C, Hoang-Xuan K, Demczuk S, Desmaze C, Plougastel B, et al. 1993. Alteration in a new gene encoding a putative membrane-organizing protein causes neuro-fibromatosis type 2. Nature 363: 515-521.

Sandquist JC, Kita AM, Bement WM. 2011. And the dead shall rise: Actin and myosin return to the spindle. Dev Cell 21: 410-419.

Saotome I, Curto M, McClatchey AI. 2004. Ezrin is essential for epithelial organization and villus morphogenesis in the developing intestine. Dev Cell 6: 855-864.

Siller KH, Doe CQ. 2009. Spindle orientation during asymmetric cell division. Nat Cell Biol 11: 365-374.

St Johnston D, Ahringer J. 2010. Cell polarity in eggs and epithelia: Parallels and diversity. Cell 141: 757-774.

ten Klooster JP, Jansen M, Yuan J, Oorschot V, Begthel H, Di Giacomo V, Colland F, de Koning J, Maurice MM, Hornbeck $\mathrm{P}$, et al. 2009. Mst4 and Ezrin induce brush borders downstream of the Lkb1/Strad/Mo25 polarization complex. Dev Cell 16: 551-562.

Thery M, Racine V, Pepin A, Piel M, Chen Y, Sibarita JB, Bornens M. 2005. The extracellular matrix guides the orientation of the cell division axis. Nat Cell Biol 7: 947-953.

Trofatter JA, MacCollin MM, Rutter JL, Murrell JR, Duyao MP, Parry DM, Eldridge R, Kley N, Menon AG, Pulaski K, et al. 1993. A novel moesin-, ezrin-, radixin-like gene is a candidate for the neurofibromatosis 2 tumor suppressor. Cell 75: 826 .

Turunen O, Wahlstrom T, Vaheri A. 1994. Ezrin has a COOHterminal actin-binding site that is conserved in the ezrin protein family. J Cell Biol 126: 1445-1453.

Van Furden D, Johnson K, Segbert C, Bossinger O. 2004. The C. elegans ezrin-radixin-moesin protein ERM-1 is necessary for apical junction remodelling and tubulogenesis in the intestine. Dev Biol 272: 262-276.

Vaughan S, Dawe HR. 2010. Common themes in centriole and centrosome movements. Trends Cell Biol 21: 57-66.

Yamada S, Pokutta S, Drees F, Weis WI, Nelson WJ. 2005. Deconstructing the cadherin-catenin-actin complex. Cell 123: 889-901.

Yamashita YM, Yuan H, Cheng J, Hunt AJ. 2010. Polarity in stem cell division: Asymmetric stem cell division in tissue homeostasis. Cold Spring Harb Perspect Biol 2: a001313. doi: 10.1101/cshperspect.a001313.

Yang HS, Hinds PW. 2003. Increased ezrin expression and activation by CDK5 coincident with acquisition of the senescent phenotype. Mol Cell 11: 1163-1176.

Yi C, Troutman S, Fera D, Stemmer-Rachamimov A, Avila JL, Christian N, Persson NL, Shimono A, Speicher DW, Marmorstein R, et al. 2011. A tight junction-associated Merlin-angiomotin complex mediates Merlin's regulation of mitogenic signaling and tumor suppressive functions. Cancer Cell 19: 527-540. 


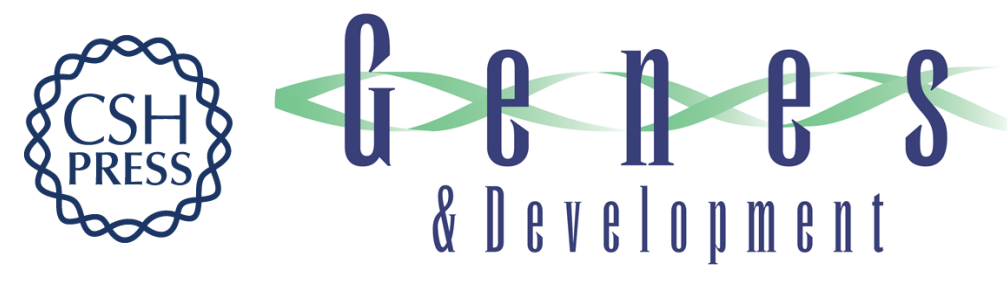

\section{Merlin/ERM proteins establish cortical asymmetry and centrosome position}

Alan M. Hebert, Brian DuBoff, Jessica B. Casaletto, et al.

Genes Dev. 2012, 26:

Access the most recent version at doi:10.1101/gad.194027.112

\section{Supplemental http://genesdev.cshlp.org/content/suppl/2012/12/18/26.24.2709.DC1 Material}

References This article cites 66 articles, 20 of which can be accessed free at: http://genesdev.cshlp.org/content/26/24/2709.full.html\#ref-list-1

\section{License}

Email Alerting

Service

Receive free email alerts when new articles cite this article - sign up in the box at the top right corner of the article or click here.

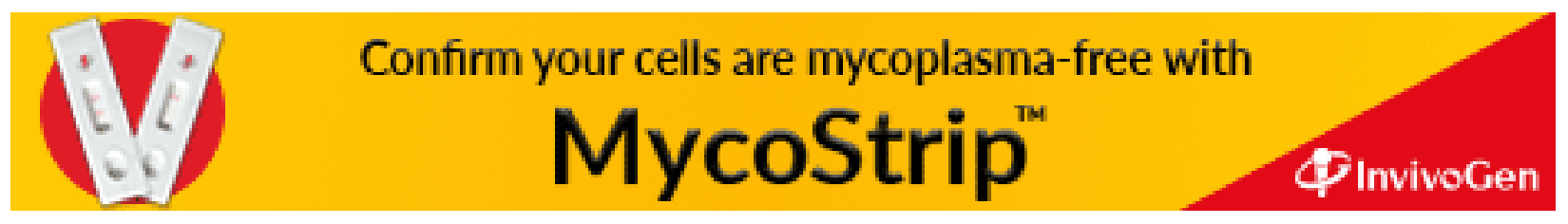

